\title{
Performance on the "aggression machine": Motivation to help or harm?
}

\author{
ROBERT A. BARON and REBECCA J. EGGLESTON \\ Purdue University, Lafayette, Ind. 47907
}

An experiment was conducted to investigate the motives underlying Ss' performance on the aggression machine. Results indicated that under the standard "learning" instructions devised by Buss, the amount of shock directed by Ss against a confederate was positively related to their expressed desires to help this individual and make the experiment a success. Thus, altruistic motives appeared to exert an important effect upon their behavior. When the experiment was described as an investigation of the effects of shock upon physiological reactions, however, the influence of such motives upon Ss' behavior was apparently eliminated. The implications of these findings for the laboratory study of human aggression are discussed.

A large number of recent experiments concerned with the topic of human aggression (e.g., Baron, 1971; Rule \& Hewitt, 1971; Zillmann, 1971) have employed some variation of a set of procedures devised by Buss (1961). During the course of these procedures, Ss are informed that they are participating in an experiment concerned with the effects of punishment on learning and instructed to deliver electric shocks to another person (a confederate of the $E$ ) on occasions when he makes "errors" in a learning task.

In studies employing these general procedures, it is assumed that the greater the intensity or duration of the shocks employed by Ss, the greater their level of aggression against the victim. However, as noted recently by Weiss (1969) and Rule \& Hewitt (1971), it is possible that Ss' use of strong or long-lasting shocks reflects their desire to help this individual master the experimental materials, rather than a motive to harm or injure him. To the extent that this is indeed the case, the validity of performance on the aggression machine as a measure of aggressive behavior may be called into question.

In view of the importance of this possibility for continued use of the Buss procedures, it seemed important to subject it to direct investigation. Thus, the present experiment was designed to obtain preliminary information concerning the motives underlying Ss' use of high magnitude shocks on the aggression machine. In order to accomplish this task, two groups of Ss performed on this apparatus under contrasting sets of instructions and then completed a questionnaire designed to assess the motives which had contributed to their behavior. In the first group, Ss were provided with the standard learning instructions devised by Buss (1961), and directed to shock the learner (i.e., the $C$ ) whenever he made an error on the learning task. It was anticipated that under these conditions, at least some Ss would assume that strong shocks would be most effective in helping the learner master the experimental materials and that, as a result, a positive correlation would exist between their expressed desire to help this individual and the magnitude of the shocks they employed. In a second group, Ss were informed that the experiment was concerned with the effects of shock upon physiological reactions and were instructed to shock the $\mathrm{C}$ on occasions designated by the $\mathrm{E}$. It was predicted that under these conditions, Ss would have no grounds for assuming that strong shocks would aid the $\mathrm{C}$ in any manner and that, as a result, there would be no relationship between the magnitude of the shocks they employed and their expressed desire to help this individual. Finally, because it seemed possible that the motives underlying Ss' performance on the aggression machine would be influenced by their degree of anger toward the victim, half of the individuals in each instruction group were angered by this individual before being provided with an opportunity to shock him. It was tentatively predicted that Ss would express a weaker desire to help the $C$ under the angry than under the nonangry condition.

\section{SUBJECTS}

Forty male undergraduates enrolled at Purdue University participated in the study. These individuals were recruited as volunteers by the members of an undergraduate class, under the restriction that they have had no courses in psychology beyond the elementary level.

\section{DESIGN AND APPARATUS}

A 2 by 2 factorial design based upon two levels of anger arousal (angry, nonangry) and two types of instructions (learning, physiological) was employed. Ten Ss were assigned randomly to each cell of this design.

The apparatus consisted of a modified Buss "aggression machine," a Lafayette stop clock (Model $20225 \mathrm{~A}$ ), and an intercom system. A more detailed description of this equipment is presented elsewhere (Baron, 1971).

\section{PROCEDURE \\ Anger Arousal}

The first phase of the study was designed to manipulate Ss' level of anger toward the victim. The procedures employed for this purpose were highly similar to those used in previous research (Baron, 1971), and will not be described in detail here. Briefly, the $S$ was asked to offer a solution to a problem posed by the $\mathrm{E}$ (how to control rising crime rates), and then presented with a written evaluation of his work ostensibly prepared by the $\mathrm{C}$. In the angry condition, the comments supplied by this individual were highly unfavorable and quite insulting, while in the nonangry condition they were quite favorable and complimentary.

Opportunity to Shock the C

Following the completion of these procedures, Ss were provided with an opportunity to deliver electric shocks of varying intensity to the $C$, under one of two different sets of instructions. In the learning instructions condition, Ss were told that the study was concerned with the effects of punishment upon learning and were instructed to shock the $C$ each time a red signal light indicated that he had made an error on the learning task. In the physiological instructions condition, they were informed that the study was concerned with the effects of shock upon physiological reactions and were directed to shock the $\mathrm{C}$ each time the same red signal light was illuminated. In order to eliminate the possibility that Ss in this group would employ high magnitude shocks in order to help the $E$ conduct a successful study, they were specifically told that any shocks they used would be completely adequate in terms of satisfying the goals of the study. In both instructions groups, the signal light was illuminated a total of 20 times, thus providing Ss with an equal number of opportunities to shock the C.1

Postexperimental Questionnaire

Following the last shock to the C, E returned and administered a brief postexperimental questionnaire to Ss. Separate items on this questionnaire required them to rate (on 7-point scales) their degree of anger toward the $C$ and the extent to which their choice of shocks was influenced by a desire to help this individual, hurt him, or help the experiment succeed. 
RESULTS

Aggression Machine Performance

As has been the case in several previous investigations (e.g., Hartmann, 1969), the total amount of noxious stimulation directed against the $C$ by $\mathrm{Ss}$ was measured in terms of the product of shock intensity by shock duration. An analysis of variance performed on these data indicated that only the main effect of anger arousal was significant ( $F=5.40$, df $=1 / 39, p<.025$ ). Thus, Ss in the angry group delivered more punishment to the $C$ than $S s$ in the nonangry condition, but performance on the aggression machine was not influenced by instructions concerning the ostensible purpose of the experiment.

\section{Questionnaire Data}

In order to obtain preliminary evidence concerning the motives underlying Ss' performance on the aggression machine, responses to the appropriate questionnaire items were correlated with the measure of shock magnitude described above. Initial analyses revealed no differences in the magnitude of these correlations in the angry and nonangry conditions. Thus, the data for these groups was combined in all subsequent analyses. The correlation coefficients of primary interest are presented in Table 1.2 Inspection of this table reveals that in the case of the learning instructions group, shock magnitude was positively related both to Ss' expressed desire to help the $C$ and to their desire to help the experiment succeed. Thus, it appears that under this condition, performance on the aggression machine was indeed influenced by what seem to be altruistic motives. In contrast, shock magnitude was negatively related to Ss' rated desire to help the $C$ and unrelated to their desire to make the experiment succeed in the case of the physiological instructions group. These findings suggest that Ss' behavior was not influenced by altruistic motives under these conditions.
Table 1

Correlations Between Questionnaire Items and Shock Marnitude

\begin{tabular}{lcc}
\hline & \multicolumn{2}{c}{ Questionnaire Item } \\
\cline { 2 - 3 } & $\begin{array}{c}\text { Desire to } \\
\text { Help the }\end{array}$ & $\begin{array}{c}\text { Desire to } \\
\text { Help the } \\
\text { Experiment } \\
\text { Instructions }\end{array}$ \\
\hline Confederate & Succed \\
Learning & $+.45^{*}$ & $+.74 \dagger$ \\
Physiological & $-.55^{* *}$ & +.01 \\
\hline
\end{tabular}

${ }^{*} p<.05, * * p<.02,+p<.01$

A final analysis performed on the data from the postexperimental questionnaire indicated that $\mathrm{Ss}$ in the angry group reported a significantly higher level of anger toward the $\mathrm{C}$ than $S s$ in the nonangry group ( $F=42.32$, df $=1 / 39, p<.001$ ).

\section{DISCUSSION}

The findings of the present study suggest that under conditions where the standard learning instructions devised by Buss (1961) are employed, performance on the aggression machine may reflect a desire on the part of Ss to help the learner or make the experiment a success. Thus, as suggested by Weiss (1969), performance on this apparatus may be strongly influenced by altruistic motives. However, the findings of several recent investigations (e.g., Shemberg, Leventhal, \& Allman, 1968; Wolfe \& Baron, 1971) suggest that the aggression machine may also measure the strength of S's desire to harm or injure the victim. It appears, therefore, that both altruistic and aggressive motives may underlie the use of high magnitude shocks on this apparatus, and that the significance of such behavior must be interpreted with a greater degree of caution than has often been the case in the past.

The negative correlation between shock magnitude and S's expressed desire to help the $C$ in the physiological instructions group suggests that describing the experiment in these terms was successful in eliminating the contribution of altruistic motives to their behavior. Thus, such procedures may prove useful in future investigations concerned with human aggression. Regardless of whether this is found to be the case, however, further attempts to clarify and refine existing procedures for the laboratory study of aggressive behavior appear to be indicated.

\section{REFERENCES}

BARON, R. A. Aggression as a function of audience presence and prior anger arousal. Journal of Experimental Social Psychology, 1971, 7, 515-523.

BUSS, A. H. The psychology of aggression. New York: Wiley, 1961 .

HARTMANN D P Influence of symbolicaliy modeled instrumental aggression and pain cues on aggressive behavior. Journal of Personality \& Social Psychology, 1969, 11, 280-288.

RULE, B. G. \& HEWITT, L. S. Effects of thwarting on cardiac response and physical aggression. Journal of Personality \& Social Psychology, 1971 . 19, 181-187.

SHEMBERG, K. M., LEVENTHAL, D. B. \& ALLMAN, L. Aggression machíne performance and rated aggression. Joumal of Experimental Research in Personality, 1969, 3, 117-119.

WEISS, W Effects of the mass media of communication. In G. Lindzey and E. Aronson (Eds.), The handbook of social psychology. Vol. 5. Reading, Mass: Addison-Wesley, 1969.

WOLFE, B. M. \& BARON, R. A Laboratory aggression related to aggression in naturalistic social situations: Effects of an aggressive model on the behavior of college student and prisoner observers. Psychonomic Science, 1971 , 24, 193-194.

ZILLMANN, D. Excitation transfer in communication-mediated aggressive behavior. Joumal of Experimental Social Psychology, 1971, 7, 419-434. NOTES

1. In order to equate the activities performed by $S s$ in the two instruction groups, individuals in the physiological condition presented the same materials (nonsense syllable pairs) to the $\mathrm{C}$ as $\mathrm{Ss}$ in the learning condition. However, they were informed that these procedures were employed simply "to take his mind off the shocks." and that there would be no relationship between his success in memorizing these materials and illumination of the red shock signal.

2. Unfortunately, so few Ss admitted to any desire to harm the $C$ that meaningful analyses could not be performed on the data for this item. 